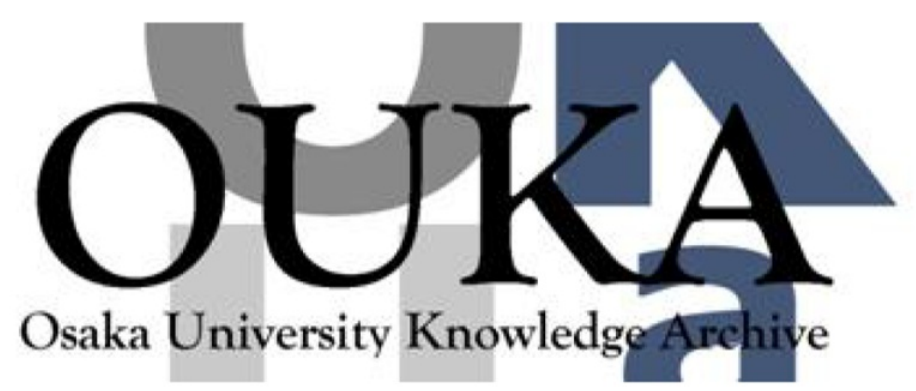

\begin{tabular}{|c|c|}
\hline Title & $\begin{array}{l}\text { Mechanism of SiN etching rate fluctuation in } \\
\text { atomic layer etching }\end{array}$ \\
\hline Author (s) & $\begin{array}{l}\text { Hirata, Akiko; Fukasawa, Masanaga; Kugimiya, } \\
\text { Katsuhisa et al. }\end{array}$ \\
\hline Citation & $\begin{array}{l}\text { Journal of Vacuum Science and Technology A: } \\
\text { Vacuum, Surfaces and Films. 38(6) p.062601 }\end{array}$ \\
\hline Issue Date & $2020-12$ \\
\hline oaire:version & VoR \\
\hline URL & https://hdl. handle. net/11094/78454 \\
\hline rights & $\begin{array}{l}\text { This article may be downloaded for personal use } \\
\text { only. Any other use requires prior permission } \\
\text { of the author and AIP Publishing. This article } \\
\text { appeared in Journal of Vacuum Science \& } \\
\text { Technology A 38, 062601 (2020) and may be found } \\
\text { at https://doi.org/10.1116/6.0000257. }\end{array}$ \\
\hline Note & \\
\hline
\end{tabular}

Osaka University Knowledge Archive : OUKA

https://ir. Library. osaka-u. ac. jp/

Osaka University 


\section{Mechanism of SiN etching rate fluctuation in atomic layer etching}

Cite as: J. Vac. Sci. Technol. A 38, 062601 (2020); https://doi.org/10.1116/6.0000257

Submitted: 14 April 2020 . Accepted: 08 September 2020 . Published Online: 09 November 2020

(D) Akiko Hirata, (D) Masanaga Fukasawa, Katsuhisa Kugimiya, Kojiro Nagaoka, Kazuhiro Karahashi, (D) Satoshi Hamaguchi, and Hayato Iwamoto

\section{COLLECTIONS}

Paper published as part of the special topic on Special Topic Collection Commemorating the Career of John Coburn COBURN2020
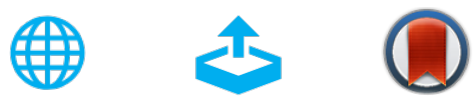

View Online

\section{ARTICLES YOU MAY BE INTERESTED IN}

Etch selectivity during plasma-assisted etching of $\mathrm{SiO}_{2}$ and $\mathrm{SiN}_{\mathbf{X}}$ : Transitioning from reactive ion etching to atomic layer etching

Journal of Vacuum Science \& Technology A 38, 050803 (2020); https://

doi.org/10.1116/6.0000395

Area-selective atomic layer deposition enabled by competitive adsorption

Journal of Vacuum Science \& Technology A 38, 062411 (2020); https://

doi.org/10.1116/6.0000497

Overview of atomic layer etching in the semiconductor industry

Journal of Vacuum Science \& Technology A 33, 020802 (2015); https://

doi.org/10.1116/1.4913379

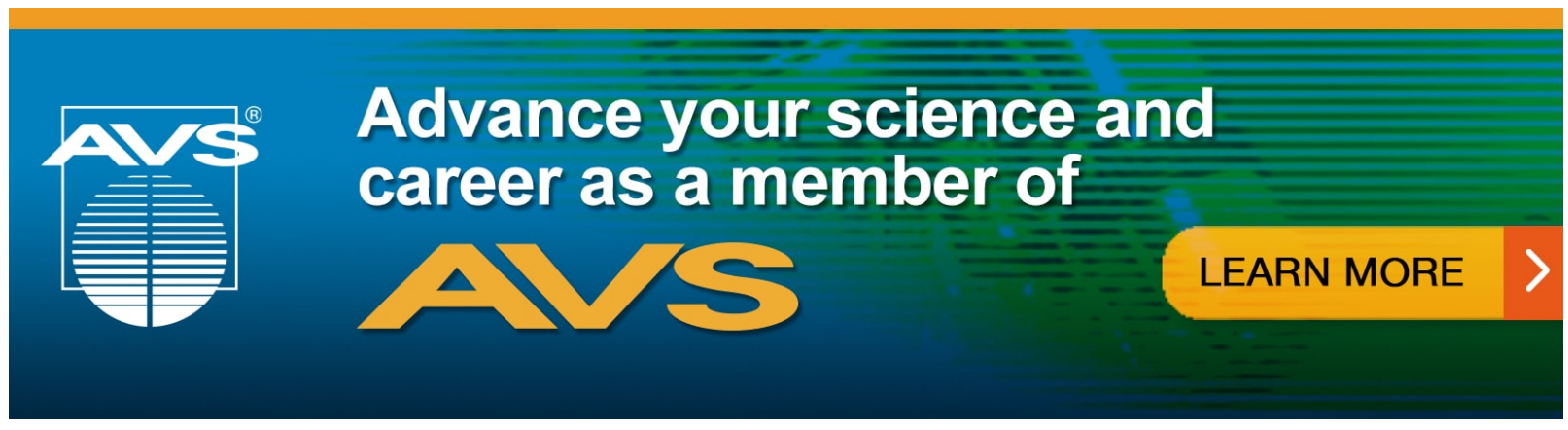




\title{
Mechanism of SiN etching rate fluctuation in atomic layer etching
}

Cite as: J. Vac. Sci. Technol. A 38, 062601 (2020); doi: $10.1116 / 6.0000257$

Submitted: 14 April 2020 - Accepted: 8 September 2020 .

Published Online: 9 November 2020

Akiko Hirata, ${ }^{1,2, b)}$ (D) Masanaga Fukasawa, ${ }^{1}$ D Katsuhisa Kugimiya, ${ }^{7}$ Kojiro Nagaoka, ${ }^{7}$ Kazuhiro Karahashi, ${ }^{2}$ Satoshi Hamaguchi, ${ }^{2}$ (D) and Hayato Iwamoto ${ }^{\top}$

\author{
AFFILIATIONS \\ ${ }^{1}$ Research Division 2, Sony Semiconductor Solutions Corporation., 4-14-1 Asahi-cho, Atsugi, Kanagawa 243-0014, Japan \\ ${ }^{2}$ Center for Atomic and Molecular Technologies, Osaka University, 2-1 Yamadaoka, Suita, Osaka 565-0871, Japan
}

Note: This paper is part of the Special Topic Collection Commemorating the Career of John Coburn.

a) This article is based on material presented at the 66th Symposium of the American Vacuum Society.

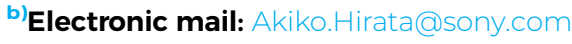

\begin{abstract}
Atomic layer etching (ALE) enables atomic-precision control of the surface reaction for device fabrication. In this study, we investigate SiN ALE with process optimization of the surface adsorption and desorption steps, and we clarify the rate fluctuation mechanism. When we attempted $\mathrm{CH}_{3} \mathrm{~F} / \mathrm{Ar}$ plasma adsorption followed by the subsequent Ar desorption step, an etch stop was observed owing to the excess deposition $(>6 \mathrm{~nm})$ of a protective film on the surface. X-ray photoelectron spectroscopy analysis revealed that a high number of $\mathrm{C}-\mathrm{C}$ bonds was detected. As the bonding energy of $\mathrm{C}-\mathrm{C}(6.4 \mathrm{eV})$ is high, these bonds remain after the desorption step. The excess C-rich polymer deposition after ALE originates from the residual $\mathrm{C}-\mathrm{C}$ bonds. To suppress the C-rich polymer deposition, we studied stable SiN ALE using a desorption step with $\mathrm{Ar} / \mathrm{O}_{2}$ plasma $(0.36 \mathrm{~nm} /$ cycle $)$ and a two-step sequential desorption with $\mathrm{Ar}$ and $\mathrm{O}_{2}$ plasma $(0.6 \mathrm{~nm} / \mathrm{cycle})$, which resulted in stable SiN ALE processes. Because the surface condition is able to fluctuate with the number of cycles, precise surface control is strongly required to achieve stable ALE. Control of the plasma-wall interaction is also important for stable SiN ALE. We intentionally changed the chamber wall conditions and found that the polymer-deposited wall caused a fluctuation of the etched amount, which resulted from $\mathrm{CF}_{x}$ desorption from the deposited polymer. Thus, it is also important to control the influence of desorbed species from the chamber components for suppression of the ALE fluctuation.
\end{abstract}

\section{Published under license by AVS. https://doi.org/10.1116/6.0000257}

\section{INTRODUCTION}

The size of semiconductor devices is continuously being scaled down, and there is a demand for the precise control of the etched profiles and a minimization of damage during dry etching. Atomic layer etching (ALE) is a promising technology that is able to overcome these issues. ${ }^{1-3}$ ALE has been widely developed in recent years with an emphasis on Si-based, ${ }^{4}$ dielectric-based, ${ }^{5-15}$ and metal-based ${ }^{16-19}$ materials processing. In this paper, we focus on ALE for dielectric films, which consists of two sequential steps: the surface adsorption of a polymer and desorption steps. The desorption step can be classified into three categories that are based on chemical, physical, and thermal desorption. To realize anisotropic etched profiles, the physical desorption by Ar plasma is discussed.
ALE for dielectric films has been developed mainly for $\mathrm{SiO}_{2}{ }^{5-9}$ One of the applications of $\mathrm{SiO}_{2}$ ALE is for high-aspect-ratio self-aligned contacts ( $\mathrm{SAC}$ ). As $\mathrm{SiO}_{2} \mathrm{ALE}$ has a higher selectivity of $\mathrm{SiO}_{2}$ over $\mathrm{SiN}$, compared with conventional continuous wave (CW) etching, better SAC profiles can be obtained. ${ }^{9} \mathrm{SiO}_{2}$ ALE has been applied to advanced logic devices for the sub-7-nm technology generation. In the $\mathrm{SiO}_{2} \mathrm{ALE}$ process, a fluorocarbon polymer is adsorbed by $\mathrm{C}_{4} \mathrm{~F}_{8} / \mathrm{Ar}$ plasma, followed by the subsequent physical desorption by Ar plasma. During desorption, by-products such as $\mathrm{SiF}_{\mathrm{x}}$ and $\mathrm{CO}_{\mathrm{x}}$ are generated. In the case of adsorption with $\mathrm{C}_{4} \mathrm{~F}_{8} / \mathrm{Ar}$ plasma, a thick polymer is deposited on the mask and underlying materials (i.e., $\mathrm{SiN}$ and $\mathrm{Si}$ ). Thus, highly selective $\mathrm{SiO}_{2}$ etching can be performed.

$\mathrm{SiN}$ is also widely used in device structures, such as in the sidewall of transistor gates and the liner-layer at the contact 
(1) Surface adsorption (2) Desorption

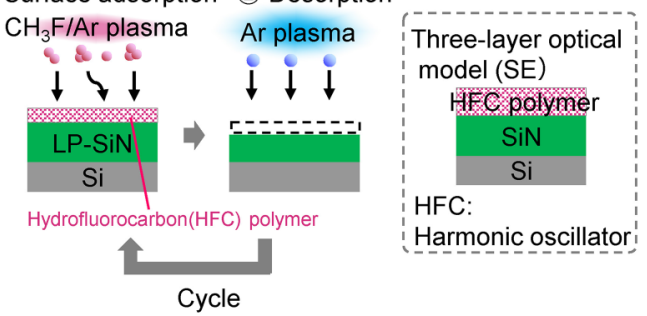

FIG. 1. Schematic of SiN ALE sequence and optical model for spectroscopic ellipsometry.

bottom. However, the number of published papers related to $\mathrm{SiN}$ ALE is much lower than that related to $\mathrm{SiO}_{2}$ ALE. Thus, we investigated the SiN ALE in detail. There are two main proposed methods of SiN ALE. The first consists of two steps: modified layer generation by $\mathrm{H}_{2}$ plasma and then removal of the modified layer. ${ }^{13-15}$ However, $\mathrm{H}_{x}{ }^{+}$ions penetrate deep into the surface even at a low energy. Thus, the $\mathrm{H}_{x}{ }^{+}$ions may cause damage to the underlying layer in device fabrication. The other is a method in which a hydrofluorocarbon (HFC) polymer is adsorbed by $\mathrm{CH}_{3} \mathrm{~F} / \mathrm{Ar}$ plasma and the reactive layer is desorbed by Ar plasma. ${ }^{10-12}$ We focus on the latter method since less damage is expected.

To date, most of the reports on SiN ALE have focused on the mechanism, and few reports have been published that discuss the issues encountered in device fabrication. However, when ALE is used for device manufacturing, process stability and suppression of fluctuation, which depend on the chamber conditions, are extremely important. $^{20,21}$ Therefore, we investigate SiN ALE stability with process optimization of the surface adsorption and desorption steps, and we clarify the rate fluctuation mechanism.

\section{EXPERIMENT}

A dual frequency capacitively coupled plasma reactor $(60 \mathrm{MHz} / 2 \mathrm{MHz}$ ) was used in this study. SiN (50 nm) was deposited on the Si substrate by low pressure chemical vapor deposition. One etching cycle consisted of two steps. $\mathrm{CH}_{3} \mathrm{~F} / \mathrm{Ar}$ plasma was applied to deposit the HFC polymer as the adsorption step. The bias power was $0 \mathrm{~W}$. The gas flow rates of $\mathrm{CH}_{3} \mathrm{~F}$ and $\mathrm{Ar}$ were 40 and 460 SCCM, respectively. Then, Ar plasma was used in the desorption step. The peak-to-peak voltage $\left(\mathrm{V}_{\mathrm{pp}}\right)$ of the bottom electrode was $330 \mathrm{~V}$ in the desorption. The high energy peak of simulated ion energy distribution function for the Ar desorption step was nearly equal to the $\mathrm{V}_{\mathrm{pp}}$. By repeating this sequence, SiN ALE was achieved (Fig. 1). The conditions for each experiment are shown in Tables I and II. The thicknesses of SiN and the HFC polymer were measured by spectroscopic ellipsometry (SE), XPS, and transmission electron microscopy (TEM). The optical constants of the HFC polymer were determined by SE. Fitting was performed using an HFC polymer with a thickness of approximately $6 \mathrm{~nm}$. A three-layer optical model (HFC polymer/ $\mathrm{SiN} / \mathrm{Si}$ ) with fixed optical constants was used for the analysis of the thicknesses. The chemical bonding of the SiN surface was analyzed by XPS. The measurement was carried out on a PHI Quantera II system using a monochromatic $\mathrm{Al}$ source $(\mathrm{h} v=1486.6 \mathrm{eV})$.

To study the interaction between the plasma and the wall surfaces, which affects the ALE stability, the chamber wall conditions were intentionally varied. ${ }^{20,21}$ As a pretreatment, cleaning was performed with $\mathrm{O}_{2}$ plasma for $300 \mathrm{~s}$. After that, irradiation with $\mathrm{C}_{4} \mathrm{~F}_{8} /$ Ar plasma was performed for 0,90 , and $180 \mathrm{~s}$ to deposit the polymer on the chamber wall. Thereafter, SiN ALE was performed to evaluate the etching rate uniformity. As the chamber wall condition will cause a $\mathrm{C} / \mathrm{F}$ density fluctuation in the plasma, the effect of the plasma-wall interactions can be analyzed.

The transition time between each step is also important to evaluate the $\mathrm{C} / \mathrm{F}$ density fluctuation in the adsorption and desorption steps. To study the effect of residual gas in the previous step, ALE was performed by changing the gas transition time between the adsorption and desorption steps. After $\mathrm{O}_{2}$ plasma cleaning as a pretreatment, we set the $\mathrm{CH}_{3} \mathrm{~F} / \mathrm{Ar}$ gas flow for $20 \mathrm{~s}$ as the gas flow stabilization step. $\mathrm{CH}_{3} \mathrm{~F} / \mathrm{Ar}$ plasma were irradiated for $4 \mathrm{~s}$ as the adsorption step. Then, as the gas transition step, Ar gas was flowed for 20 or $1 \mathrm{~s}$. In the following desorption step, Ar plasma was irradiated for $60 \mathrm{~s}$, and finally $\mathrm{O}_{2}$ flash was performed to evaluate the etching rate uniformity.

There are no error bars in the graphs due to insufficient data point. However, all of experiments were performed in the mass production tool that is strictly controlled to keep the sufficient

TABLE I. Experiment.

\begin{tabular}{lcccc}
\hline \hline & & Adsorption & & \\
\cline { 2 - 5 } Experiment & Pressure (mTorr) & Gas flow rate (SCCM) & Ion energy (eV) & Time (s) \\
\hline (a) Adsorption & 40 & $\mathrm{CH}_{3} \mathrm{~F} / \mathrm{Ar}=40 / 460$ & $\sim 25$ & $4,8,12$ \\
(b) Adsorption $(\mathrm{s})$
\end{tabular}


TABLE II. Experiment.

\begin{tabular}{|c|c|c|c|c|c|c|c|c|c|}
\hline \multirow[b]{2}{*}{ Experiment } & \multicolumn{4}{|c|}{ Desorption } & \multicolumn{4}{|c|}{$\mathrm{O}_{2}$ ashing } & \multirow[b]{2}{*}{ Cycle No. } \\
\hline & $\begin{array}{l}\text { Pressure } \\
\text { (mTorr) }\end{array}$ & $\begin{array}{c}\text { Gas flow rate } \\
(\mathrm{SCCM})\end{array}$ & $\begin{array}{c}\text { Ion } \\
\text { energy } \\
(\mathrm{eV})\end{array}$ & $\begin{array}{c}\text { Time } \\
(s)\end{array}$ & $\begin{array}{l}\text { Pressure } \\
\text { (mTorr) }\end{array}$ & $\begin{array}{c}\text { Gas flow } \\
\text { rate } \\
(\mathrm{SCCM})\end{array}$ & $\begin{array}{c}\text { Ion } \\
\text { energy } \\
(\mathrm{eV})\end{array}$ & $\begin{array}{l}\text { Time } \\
(\mathrm{s})\end{array}$ & \\
\hline (a) Adsorption & & & & & & & & & 1 \\
\hline (b) Adsorption & & & & & & & & & 1 \\
\hline (c) ALE & 40 & $\mathrm{Ar}=500$ & 330 & 10 & & & & & $1,2,3,5,10$ \\
\hline (d) ALE w/O 2 desorption & 40 & $\mathrm{O}_{2} / \mathrm{Ar}=50 / 450$ & 300 & 60 & & & & & $1,5,8,10$ \\
\hline (e) $\mathrm{ALE} \mathrm{w} / \mathrm{O}_{2}$ ashing & 40 & $\mathrm{Ar}=500$ & 330 & 60 & 40 & $\mathrm{O}_{2}=500$ & 300 & 10 & $1,5,8,10$ \\
\hline (f) ALE (plasma-wall interaction) & 40 & $\operatorname{Ar}=500$ & 330 & 60 & & & & & 5 \\
\hline (g) ALE (gas transition study) & 40 & $\operatorname{Ar}=500$ & 330 & 60 & & & & & 5 \\
\hline
\end{tabular}

repeatability of etching performances. Thus, it is confirmed that all of our experimental results are repeatable.

\section{RESULTS AND DISCUSSION}

\section{A. Accuracy evaluation of film thickness measurements}

The film thickness was evaluated using SE; however, there was an issue with the measurement accuracy because the film thicknesses were extremely thin. Therefore, the accuracy of the film thickness measurement was evaluated by XPS and TEM. In XPS, the HFC polymer thickness $\left(\mathrm{d}_{H F C}\right)$ was calculated from the $\mathrm{Si}(2 \mathrm{p})$ peak area ratio of the $\mathrm{SiN}$. The decrease in $\mathrm{Si}(2 \mathrm{p})$ intensity, absorbed by the upper HFC polymer, was compared with that of the initial SiN. ${ }^{22,23}$ The formula for the HFC polymer thickness is as follows:

$$
d_{H F C}=-\lambda_{S i(2 \mathrm{p})} \ln \left(\frac{I_{S i(2 \mathrm{p})}}{I_{S i(2 \mathrm{p})}^{r e f}}\right) .
$$

Here, $\lambda_{\mathrm{Si}(2 \mathrm{p})}$ is the mean free path of the Si (2p) photoelectrons in the HFC polymer layer. $\lambda_{\mathrm{Si}(2 \mathrm{p})}$ was set as $2.5 \mathrm{~nm}$ in this study. The Si (2p) peak areas of the HFC polymer/SiN sample and initial sample are $I_{\mathrm{Si}(2 \mathrm{p})}$ and reference of $I_{\mathrm{Si}(2 \mathrm{p})}$, respectively. Matsui et al. ${ }^{23}$ reported an assumed escape depth $\left[\lambda_{\mathrm{Si}(2 \mathrm{p})}\right]$ of $3 \mathrm{~nm}$. The difference was proposed to result from the composition variations of the HFC polymer. The densification by sputtering in Ar plasma desorption might be the origin of the escape depth decrease in this experiment. After the Ar plasma desorption step, many $\mathrm{C}-\mathrm{C}$ bonds were generated in the HFC polymer, compared with $\mathrm{CH}_{3} \mathrm{~F} / \mathrm{Ar}$ plasma. Figure 2(a) shows the HFC polymer thickness measured by SE and XPS. Figure 2(b) shows the thicknesses measured by TEM. These figures confirmed that there was a correlation between the HFC polymer film thickness measured by SE, XPS, and TEM. Therefore, the film thickness of the HFC polymer can be measured with high accuracy by SE.

Under the HFC polymer, the modified-SiN layer was generated as shown in Fig. 2(b). This layer was assumed to comprise of mainly $\mathrm{Si}$ and $\mathrm{N}$ since SE results show that the optical constant of this layer is similar to that of SiN films. This layer could also contain some mixture of $\mathrm{C}, \mathrm{F}$, and $\mathrm{H}$. The thickness of the modified-SiN layer is assumed to be defined by the Ar penetration depth and dose in the desorption step. Further study is required to understand the modified layer generation during ALE because the modified layer generation is important to understand the ALE surface reactions.

(a)

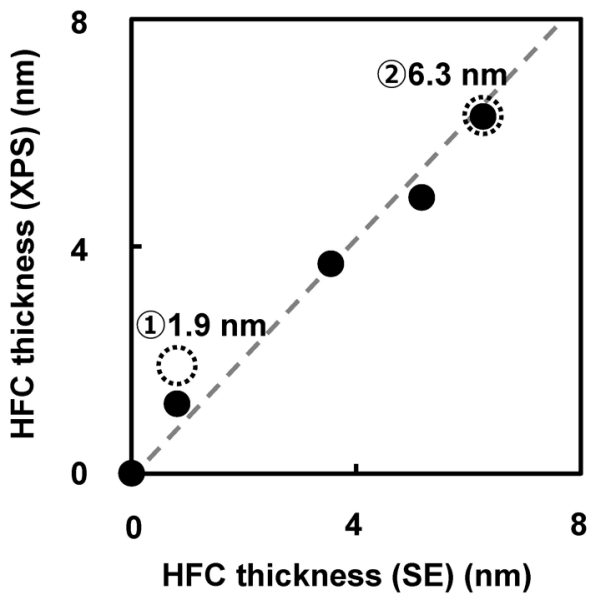

(b)

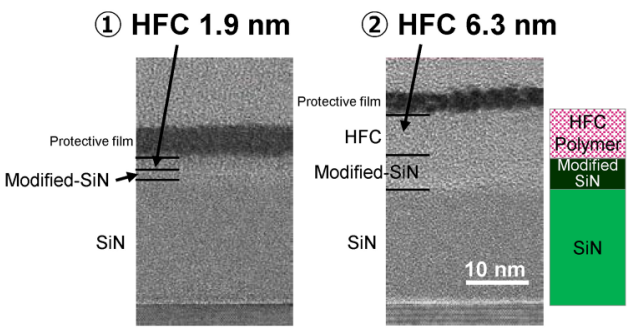

FIG. 2. (a) HFC polymer thicknesses after the adsorption step, measured by XPS vs SE. Dotted circles denote the thicknesses measured by TEM and (b) TEM images (two different process times) [experimental condition; Tables I and II (a)]. 
(1) Surface adsorption
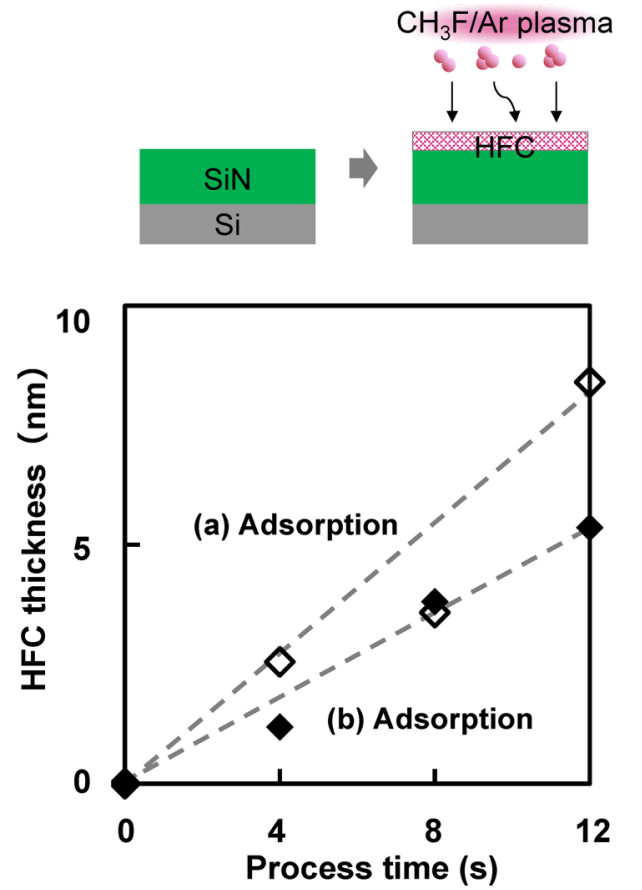

FIG. 3. HFC thicknesses as a function of adsorption process time [experimental condition; Tables I and II (a) and (b)].

\section{B. SiN ALE etch stop}

We studied the optimization of the adsorption step. An HFC film with a thickness of $2 \mathrm{~nm}$ was used in a previous study. ${ }^{11}$ Thus, the target of the HFC thickness was set to be $2 \mathrm{~nm}$. Figure 3 shows the HFC thicknesses as a function of the process time. The HFC thickness increased linearly with the process time. A 2.6-nm-thick HFC polymer, deposited on SiN, was used as the adsorption step. The desorption time by Ar plasma was set to $10 \mathrm{~s}$. By using this ALE sequence, we studied the cycle number dependence of SiN ALE. The cycle number was changed from 0 to 10 . Figure 4 shows the cycle number dependence of the film thickness change of HFC and $\mathrm{SiN}$. The etched amount for one cycle was $0.58 \mathrm{~nm}$. Etching proceeded up to two cycles; however, we observed an etch stop of $\mathrm{SiN}$ after ten cycles of ALE, owing to the deposition $(>6 \mathrm{~nm})$ of a protective film on the surface. To study the etch-stop phenomena in detail, certain changes to the conditions were also studied (not shown here). In the case of thin HFC adsorption $(1.2 \mathrm{~nm})$, an etch stop was also observed regardless of conditions. When the desorption times were changed from 10 to $60 \mathrm{~s}$, we also observed an etch stop. It was concluded that the etch stop is an important issue for stable SiN ALE.

\section{Analysis of etch-stop mechanism}

To investigate the etch-stop mechanism, the chemical bonding on the SiN surface after one and ten cycles was analyzed
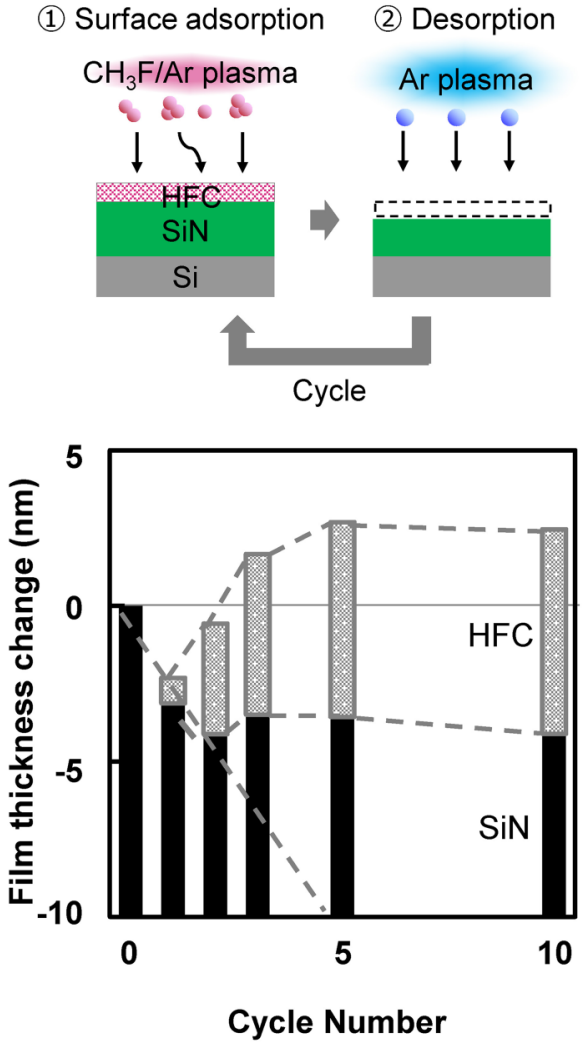

FIG. 4. Cycle number dependence of surface location of HFC and SiN [experimental condition; Tables I and II (c)].

by XPS. Figure 5 shows the $\mathrm{C}$ (1s) peak which is decomposed into each chemical bond. The binding energies of $\mathrm{C}-\mathrm{C}, \mathrm{C}-\mathrm{N}$, and $\mathrm{C}-\mathrm{F}$ were $284.8,286.3$, and $287.4 \mathrm{eV}$, respectively. Figure 5(c) shows the cycle number dependence of the peak area ratio of each bond to the total C (1s) XPS spectra. The ratio of C-C bonds increased with the cycle number of ALE. The bond strength of the C-C bond is $6.4 \mathrm{eV}$.

It is known that carbon atoms in amorphous carbon films (a-C) hybridize their outermost $\mathrm{s}$ and $\mathrm{p}$ orbitals of carbon into $s p^{3}$ and $s p^{2}$ hybrids. Thus, we investigated the $s p^{3}$ and $s p^{2}$ hybrids by $\mathrm{C}(1 \mathrm{~s})$ spectrum. The binding energy of $s p^{3}$ in a-C is $285.2 \mathrm{eV}$, and the binding energy of $s p^{2}$ is $284.4 \mathrm{eV}^{24,25}$ The binding energy of $s p^{3}$ and $s p^{2}$ was added to Fig. 5(a), and we found that it forms an $s p^{3}$ hybrid orbital (similar to diamondlike carbon). Therefore, the HFC polymer, which has many $\mathrm{C}-\mathrm{C}$ bonds, is difficult to sputter, which results in the etch stop of SiN ALE.

In Fig. 2(b), the modified-SiN layer was generated under the HFC polymer. During air exposure, the oxygen containing layer is also possible to generate under the HFC polymer. Thus, we investigated the $\mathrm{C}-\mathrm{O}$ and $\mathrm{Si}-\mathrm{O}$ related peaks in the $\mathrm{C}(1 \mathrm{~s})$ and $\mathrm{O}(1 \mathrm{~s})$ XPS spectra. However, it was found that the oxidation of modified layer under the HFC polymer is of nondetectable level. Thus, we 
(a) Cycle number : 1

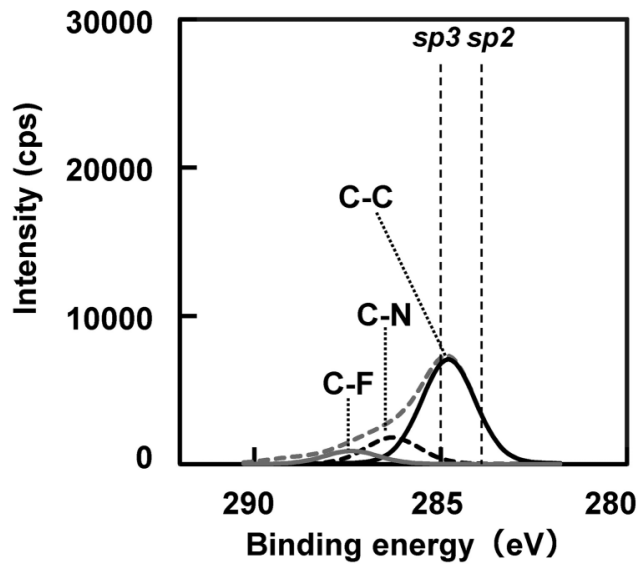

(b) Cycle number : 10

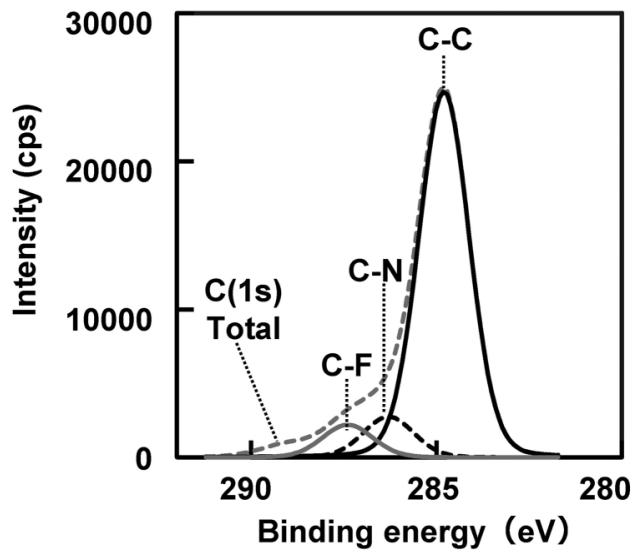

(c)

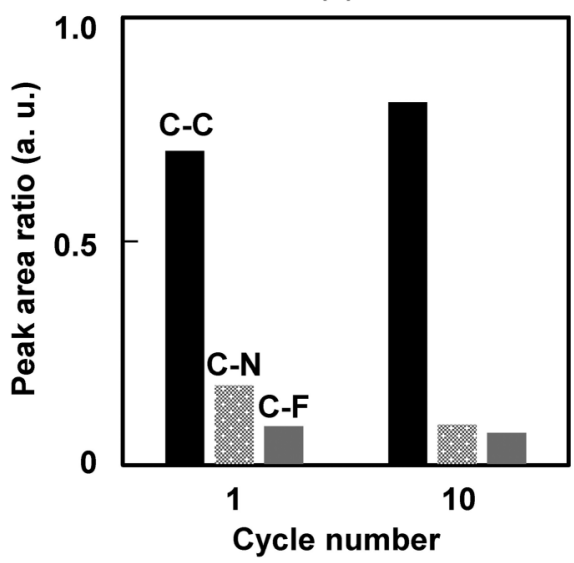

FIG. 5. (a) XPS spectra of $\mathrm{C}(1 \mathrm{~s})$ electron emission on adsorbed HFC layers after one-cycle ALE process and (b) ten-cycle ALE process. The electrons were collected at $90^{\circ}$, and (c) decomposed C-C, C-N, and C-F bond area ratio as a function of cycle number of ALE. concluded that the modified layer under the HFC polymer is the modified-SiN layer as shown in Fig. 2(b).

Figure 6 shows a schematic of the etch-stop model after adsorption, and after one cycle and ten cycles of ALE. In the adsorption step, the HFC polymer was deposited on SiN. After one cycle of ALE, it was difficult to remove the carbon completely. Strong $\mathrm{C}-\mathrm{C}$ bonds remained at the surface. After ten cycles, a thick layer of carbon polymer was deposited on the residual carbon. When ions from the plasma pass through the polymer during etching, approximately $200 \mathrm{eV}$ of kinetic energy of the incident ion is reported to be lost in a polymer with a thickness of $1 \mathrm{~nm} .{ }^{26} \mathrm{At}$ $330 \mathrm{eV}$, which is maximum ion energy of our experimental condition, etching progresses when the polymer thickness is less than $1.5 \mathrm{~nm}$, and etching stops when the film thickness exceeds $1.5 \mathrm{~nm}$ from the published results. As shown in Fig. 4, etching progresses through the HFC polymer with a thickness of $0.81 \mathrm{~nm}$ at cycle 1 . It is expected that etching will proceed when there is energy above $162 \mathrm{eV}$, in the case that the polymer film thickness is $0.81 \mathrm{~nm}$. However, the ALE ceased after cycle 2 since the polymer thickness of $3.55 \mathrm{~nm}$ is much thicker than the threshold thickness of $1.5 \mathrm{~nm}$. Thus, these results are almost consistent with the previous data, published by Tatsumi et al. The detailed study of energy loss rate differences in the polymer is a topic of future research, as our study is a rough estimate.

Thus, a thick carbon layer causes an etch stop, and suppression of $\mathrm{C}$ deposition is required for stable SiN ALE.

Although we focused on the effect of the $\mathrm{C}-\mathrm{C}$ bond in the HFC polymer, there are other possibilities that can cause the etch stop of SiN ALE. Another possible reason is that $\mathrm{Si}-\mathrm{C}$ bonds are formed on the surface. ${ }^{27-29}$ As the binding energy of $\mathrm{Si}-\mathrm{C}$ in the $\mathrm{C}$ (1s) photoemission $(283.0 \mathrm{eV})$ is close to the peak position of a strong C-C $(284.8 \mathrm{eV})$ bond, it was difficult to deconvolute the effect of $\mathrm{Si}-\mathrm{C}$. As $\mathrm{Si}-\mathrm{C}$ is generated in the interface between HFC polymer and underlying $\mathrm{SiN}$, the signal of $\mathrm{Si}-\mathrm{C}$ seems to be under the detectable-level since the upper HFC polymer suppressed the photoelectron from the interface. Further study will be performed related to the $\mathrm{Si}-\mathrm{C}$ bond by using other techniques.

\section{Proposed sequence for stable ALE}

For the suppression of excess carbon, physical removal by ion or chemical processes is two possible methods to realize stable ALE. In the case of physical removal using ions, however, longer $\mathrm{Ar}$ exposure caused sputtering of the underlayer. Therefore, we focused on the chemical removal. Desorption by $\mathrm{O}_{2} / \mathrm{Ar}$ plasma and three-step ALE with $\mathrm{O}_{2}$ ashing processes were investigated. Although the desorption by $\mathrm{O}_{2}$ plasma has been reported for $\mathrm{SiO}_{2}$ ALE, ${ }^{30} \mathrm{SiN}$ ALE with an $\mathrm{O}_{2}$-based process has not been reported (to the best of our knowledge).

To investigate the effect of oxygen, the desorption step with $\mathrm{O}_{2} / \mathrm{Ar}$ plasma was examined. The desorption time was $60 \mathrm{~s}$ and $0-10$ cycles of ALE were performed. Figure 7 shows the etched amount per cycle (EPC) as a function of cycle number in the case of a desorption step by $\mathrm{O}_{2} / \mathrm{Ar}$ plasma. The EPC was $0.89 \mathrm{~nm} /$ cycle. SiN ALE proceeded continuously by the $\mathrm{O}_{2} / \mathrm{Ar}$ plasma desorption step. The HFC polymer deposition was suppressed by $\mathrm{O}_{2}$ addition. Next, we examined a three-step ALE with $\mathrm{O}_{2}$ ashing. The desorption and ashing times 


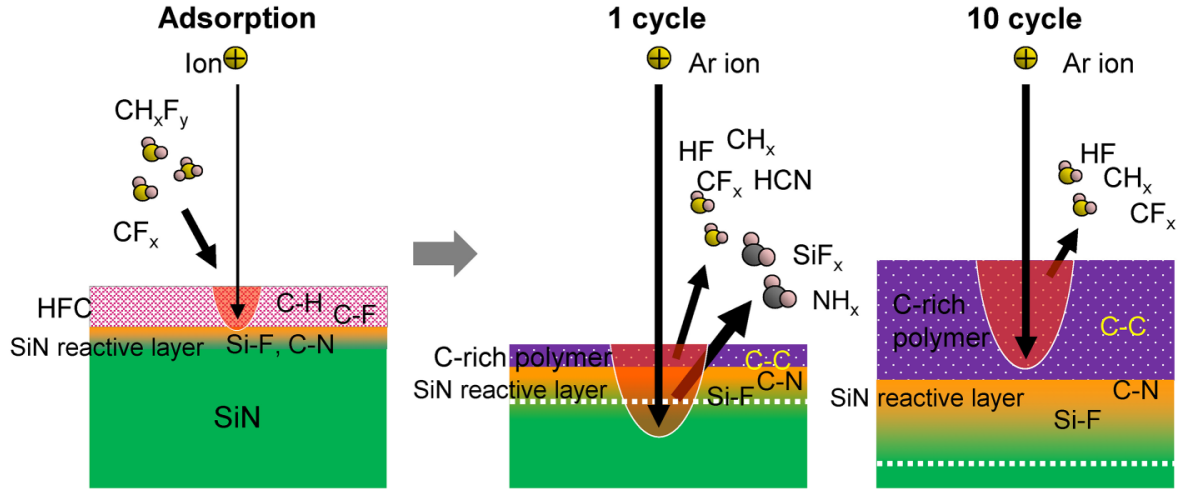

FIG. 6. Schematic models after the adsorption step, one-cycle ALE, and ten-cycle ALE. were 60 and $10 \mathrm{~s}$, and $0-10$ cycles of ALE were performed. Figure 8 shows the EPC as a function of cycle number in the case of the threestep ALE with $\mathrm{O}_{2}$ ashing. The EPC was $1.52 \mathrm{~nm} /$ cycle. Therefore, the $\mathrm{O}_{2}$ ashing step effectively removed the HFC polymer.

The EPC of the three-step ALE was much higher than that of $\mathrm{O}_{2} /$ Ar desorption. We discuss the amount of fluorine during ALE because the EPC of SiN is strongly related to the amount of fluorine on the SiN surface. The high EPC of the three-step ALE was caused by the presence of abundant fluorine atoms in the HFC during Ar desorption, compared with $\mathrm{O}_{2} / \mathrm{Ar}$ desorption. In the case of the three-step ALE with $\mathrm{O}_{2}$ ashing, the HFC film remained in the desorption step. This caused the high EPC of SiN ALE. In
(1) Surface adsorption

\section{(2) Desorption}

$\mathrm{CH}_{3}$ F/Ar plasma
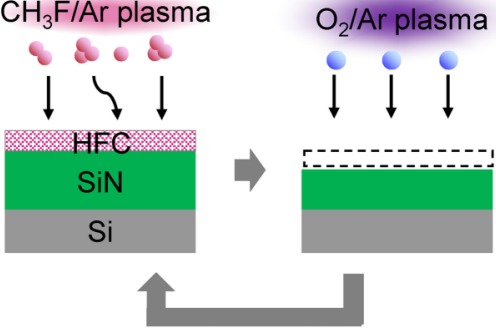

Cycle

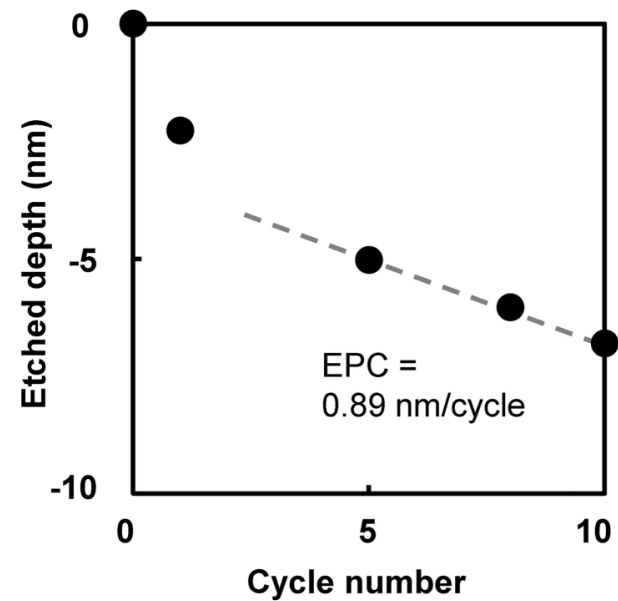

FIG. 7. Etched depths as a function of cycle number in the case of a desorption step by $\mathrm{O}_{2} /$ Ar plasma [experimental condition; Tables I and II (d)].
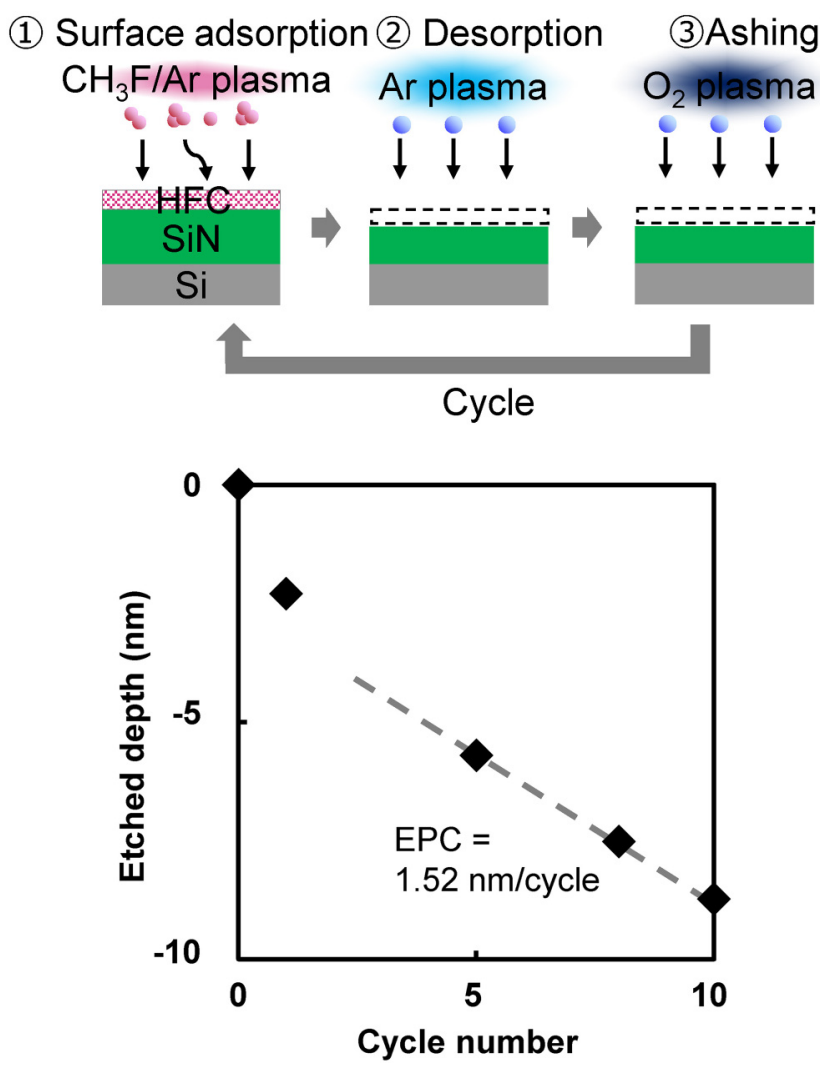

FIG. 8. Etched depths as a function of cycle number in the case of three-step ALE with subsequent $\mathrm{O}_{2}$ ashing [experimental condition; Tables I and II (e)]. 


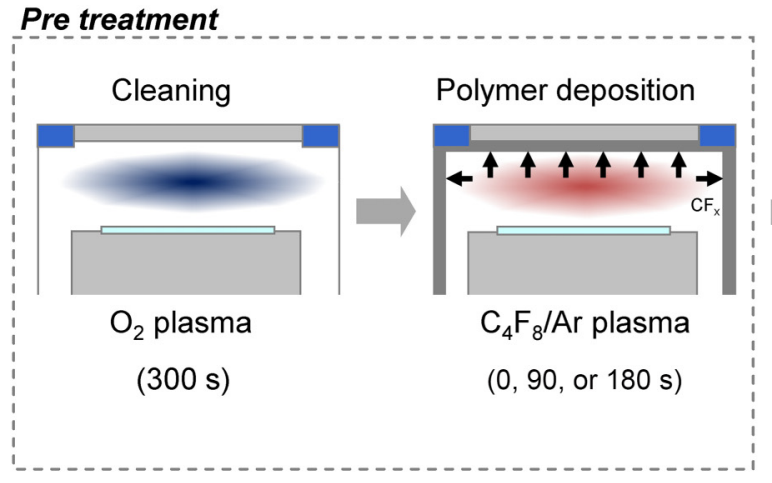

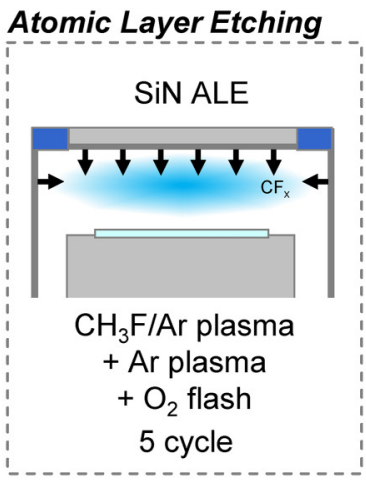

FIG. 9. Schematic of the experiment to investigate the plasma-wall interactions. The chamber conditions were intentionally varied. the case of $\mathrm{O}_{2} / \mathrm{Ar}$ desorption, the HFC was removed simultaneously during the desorption step. This caused the low EPC. As the three-step ALE is appropriate for device manufacturing, we used three-step ALE in the subsequent investigations. We also confirmed that EPC of first and second cycles was higher than that for the other cycles. Impurities from the plasma, which were implanted in the SiN surface during ALE cycles, modified the SiN surface to cause the decrease of the SiN EPC with additional cycles.

\section{E. SiN ALE fluctuation}

A key parameter of SiN ALE is the amount of fluorine, which dominantly contributes to SiN etching. In addition, the amount of carbon affects the EPC fluctuation in ALE. Excess carbon causes the etch stop and less carbon may cause the low EPC. As the amounts of fluorine and carbon are important, the effect of density fluctuations by $\mathrm{C} / \mathrm{F}$ species was studied.

As the plasma-wall interactions were reported to cause the $\mathrm{C} /$ $\mathrm{F}$ density fluctuation, ${ }^{21,22}$ the chamber wall condition was intentionally changed. We performed the $\mathrm{O}_{2}$ cleaning and polymer deposition with $\mathrm{C}_{4} \mathrm{~F}_{8} / \mathrm{Ar}$ plasma. The deposition time was 0 , 90, or $180 \mathrm{~s}$. Then, we performed the SiN ALE for five cycles using the same conditions (Fig. 9). Figure 10 shows the etched depth uniformity differences with and without chamber wall polymer deposition. The etched depth at the wafer edge increased drastically. We proposed that the desorbed species from the wall surface affected the etch rate fluctuation. Because $\mathrm{CF}_{2}$, measured by appearance mass spectroscopy, is reported to be desorbed from the deposited polymer with Ar ion injection, ${ }^{31}$ desorbed $\mathrm{CF}_{2}$ enhance the EPC at the wafer edge during $\mathrm{Ar}$ desorption. When we investigated the optical emission spectra of $\mathrm{CF}_{2}(\lambda=262.5 \mathrm{~nm})$ during the Ar desorption step (not shown here), a clear increase of the $\mathrm{CF}_{2}$ radical was detected with the chamber wall deposited conditions. In the case of $\mathrm{O}_{2}$ cleaning, however, the $\mathrm{CF}_{2}$ desorption from the chamber wall was suppressed. We concluded that the chamber wall condition is important for stable ALE processes. Under the condition that there was no deposition on the reactor wall, the etched depth uniformity across the wafer was poor. However, it can be improved by optimizing the $\mathrm{Ar}$ desorption process.

Next, we studied the effect of residual gases from the previous step. A mixture of residual gas from the previous step might cause
$\mathrm{C} / \mathrm{F}$ density fluctuation. We changed the gas transition time before the Ar desorption step from 20 to $1 \mathrm{~s}$ (Fig. 11). Figure 12 shows the etched depth uniformity differences at gas transition times of 1 and $20 \mathrm{~s}$ as a function of wafer coordinate. There was almost no difference in etched depth after ALE (adsorption and desorption) with
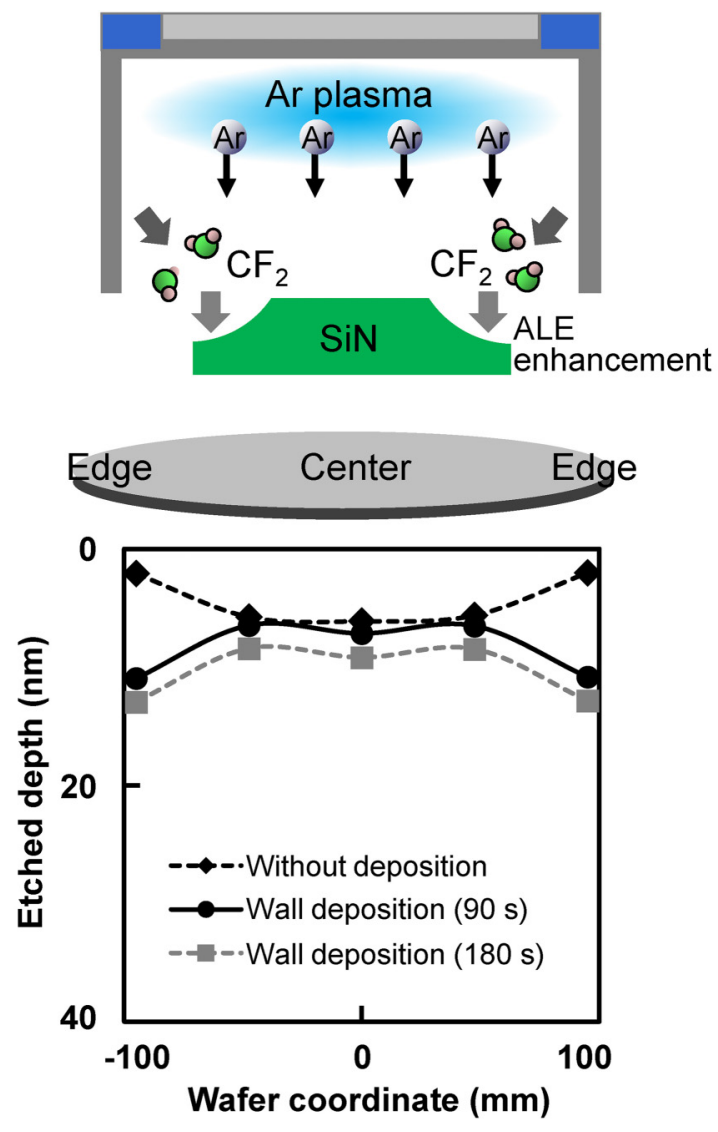

FIG. 10. Etched depth uniformity differences with and without polymer deposition on the chamber wall [experimental condition; Tables I and II (f)]. 


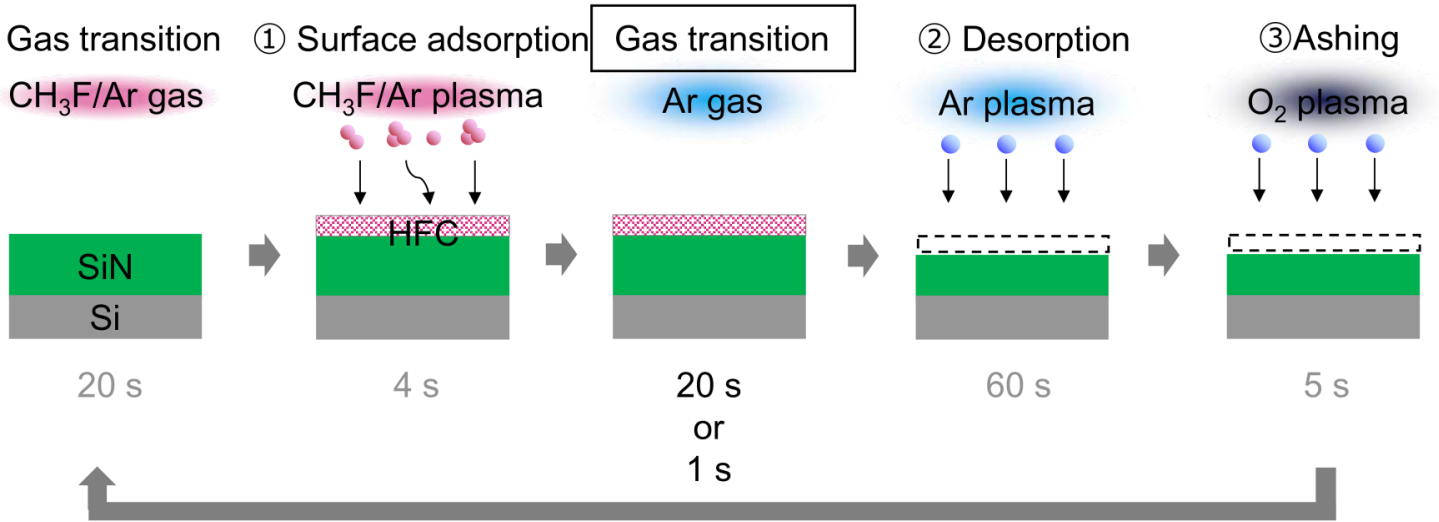

5 cycle

FIG. 11. Schematic illustration of experiments for gas transition time dependence.

gas transition times of 20 and $1 \mathrm{~s}$. We found that residual gases have almost no impact on ALE because the gas residence time under the experimental condition was $63 \mathrm{~ms}$, which is much shorter than the gas transition time $(1 \mathrm{~s})$. Therefore, the transition time has a negligible effect on the etched depth fluctuation.

We proposed the fluctuation model of SiN ALE caused by the plasma-wall interaction. $\mathrm{CF}_{2}$ desorption from the chamber wall caused the ALE enhancement. Therefore, we need to clean the chamber before ALE. We found that control of fluorine and carbon amounts is critical for stable SiN ALE.

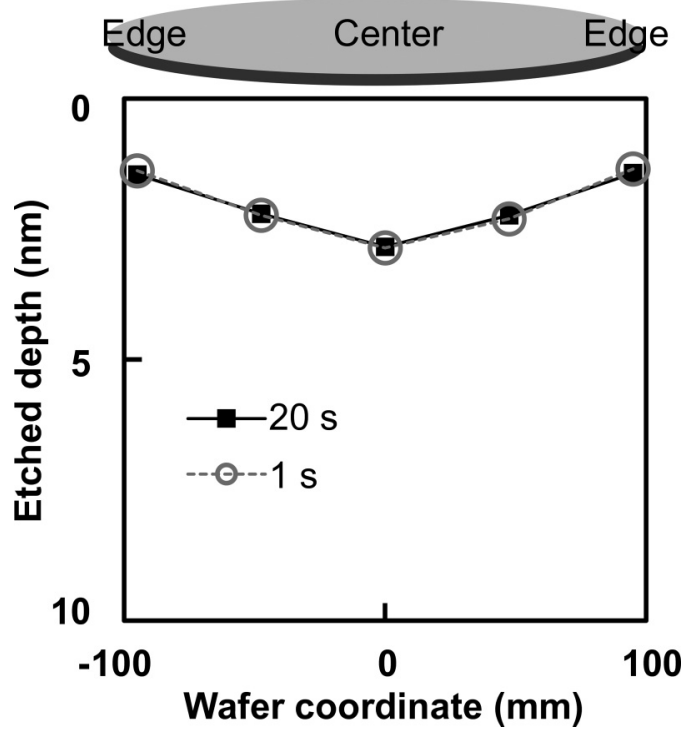

FIG. 12. Etched depth uniformities as a function of wafer coordinate with different gas transition time (20 vs. $1 \mathrm{~s}$ ) [experimental condition; Tables I and II (g)].

\section{SUMMARY AND CONCLUSIONS}

ALE has been studied extensively for surface reactions, and thus, little has been reported about the fluctuation of ALE performances in device fabrication. In this study, we investigated SiN ALE with process optimization of the adsorption and desorption steps, and we focus on the cycle number dependence of EPC fluctuation of ALE. We also studied the ALE performance variation caused by the chamber wall conditions. Our findings are as follows.

(1) Excess polymer deposition, which originates from residual carbon after desorption step, causes the etch stop of SiN ALE. The reason of residual carbon is that the HFC polymer, which has many $\mathrm{C}-\mathrm{C}$ bonds, is difficult to sputter. Thus, a thick carbon layer causes an etch stop, and suppression of $\mathrm{C}$ deposition is required for stable SiN ALE.

(2) Addition of $\mathrm{O}_{2}$ to the desorption step or a three-step $\mathrm{O}_{2}$ ashing process can suppress $\mathrm{C}$ deposition and realize stable ALE. The high EPC of the three-step ALE was caused by the presence of abundant fluorine atoms in the HFC during Ar desorption, compared with $\mathrm{O}_{2} / \mathrm{Ar}$ desorption. Hence, the three-step ALE is appropriate for device manufacturing.

(3) $\mathrm{CF}_{\mathrm{x}}$ desorption from the chamber wall causes etch enhancement of ALE. The desorbed $\mathrm{CF}_{2}$ enhance the EPC at the wafer edge during Ar desorption. We found that control of fluorine and carbon amounts is critical for stable SiN ALE.

To realize stable SiN ALE, it is necessary to keep the same surface conditions in every cycle. It is also important to control the influence of desorbed species from the chamber components. As the etching selectivity to other materials is critical for semiconductor device manufacturing, further study related to the selectivity to mask and/or underlying materials is strongly required in the near future. 


\section{REFERENCES}

${ }^{1}$ K. J. Kanarik, T. Lill, E. A. Hudson, S. Sriraman, S. Tan, J. Marks, V. Vahedi, and R. A. Gottscho, J. Vac. Sci. Technol. A 33, 020802 (2015).

${ }^{2}$ K. J. Kanarik et al., J. Vac. Sci. Technol. A 35, 05C302 (2017).

${ }^{3}$ K. J. Kanarik, S. Tan, and R. A. Gottscho, J. Phys. Chem. Lett. 9, 4814 (2018).

${ }^{4}$ Y. Horiike, T. Tanaka, M. Nakano, S. Iseda, H. Sakaue, A. Nagata, H. Shindo, S. Miyazaki, and M. Hirose, J. Vac. Sci. Technol. A 8, 1844 (1990).

${ }^{5}$ D. Metzler, R. L. Bruce, S. Engelmann, E. A. Joseph, and G. S. Oehrlein, J. Vac. Sci. Technol. A 32, 020603 (2014).

${ }^{6}$ D. Metzler, C. Li, S. Engelmann, R. L. Bruce, E. A. Joseph, and G. S. Oehrlein, J. Vac. Sci. Technol. A 34, $01 \mathrm{~B} 101$ (2016).

${ }^{7}$ D. Metzler et al., J. Vac. Sci. Technol. A 34, 01 B102 (2016).

${ }^{8}$ K.-Y. Lin, C. Li, S. Engelmann, R. L. Bruce, E. A. Joseph, D. Metzler, and G. S. Oehrlein, J. Vac. Sci. Technol. A 36, 040601 (2018).

${ }^{9}$ M. Honda, T. Katsunuma, M. Tabata, A. Tsuji, T. Oishi, T. Hisamatsu, S. Ogawa, and Y. Kihara, J. Phys. D Appl. Phys. 50, 234002 (2017).

${ }^{10} \mathrm{C}$. Li, D. Metzler, C. S. Lai, E. A. Hudson, and G. S. Oehrlein, J. Vac. Sci. Technol. A 34, 041307 (2016).

${ }^{11}$ Y. Ishii, K. Okuma, T. Saldana, K. Maeda, N. Negishi, and J. Manos, Jpn. J. Appl. Phys. 56, 06HB07 (2017).

${ }^{12}$ A. Hirata, M. Fukasawa, K. Kugimiya, K. Nagaoka, K. Karahashi, S. Hamaguchi, and H. Iwamoto, Jpn. J. Appl. Phys. 59, SJJC01 (2020).

${ }^{13}$ N. Posseme, V. Ah-Leung, O. Pollet, C. Arvet, and M. Garcia-Barros, J. Vac. Sci. Technol. A 34, 061301 (2016).

${ }^{14}$ S. D. Sherpa and A. Ranjan, J. Vac. Sci. Technol. A 35, 01 A102 (2017).

${ }^{15} \mathrm{~K}$. Nakane, R. H. J. Vervuurt, T. Tsutsumi, N. Kobayashi, and M. Hori, ACS Appl. Mater. Interfaces 11, 37263 (2019).

${ }^{16}$ A. Hirata, M. Fukasawa, T. Shigetoshi, M. Okamoto, K. Nagahata, H. Li, K. Karahashi, S. Hamaguchi, and T. Tatsumi, Jpn. J. Appl. Phys. 56, 06HD02 (2017).
${ }^{17}$ A. Hirata, M. Fukasawa, K. Nagahata, H. Li, K. Karahashi, S. Hamaguchi, and T. Tatsumi, Jpn. J. Appl. Phys. 57, 06JB02 (2018).

${ }^{18}$ T. Sasaki, K. Matsuda, M. Omura, I. Sakai, and H. Hayashi, Jpn. J. Appl. Phys. 54, $06 \mathrm{~GB} 03$ (2015).

${ }^{19} \mathrm{~N}$. Marchack, J. Innocent-Dolor, M. Hopstaken, and S. Engelmann, J. Vac. Sci. Technol. A 38, 022609 (2020).

${ }^{20}$ M. Schaepkens, R. C. M. Bosch, T. E. F. M. Standaert, G. S. Oehrlein, and J. M. Cook, J. Vac. Sci. Technol. A 16, 2099 (1998).

${ }^{21}$ M. Fukasawa, A. Kawashima, N. Kuboi, H. Takagi, Y. Tanaka, H. Sakayori, K. Oshima, K. Nagahata, and T. Tatsumi, Jpn. J. Appl. Phys. 48, 08HC01 (2009).

${ }^{22}$ T. E. F. M. Standaert, M. Schaepkens, N. R. Rueger, P. G. M. Sebel, G. S. Oehrlein, and J. M. Cook, J. Vac. Sci. Technol. A 16, 239 (1998).

${ }^{23}$ M. Matsui, F. Uchida, M. Kojima, T. Tokunaga, F. Yano, and M. Hasegawa, J. Vac. Sci. Technol. A 20, 117 (2002).

24 J. Díaz, G. Paolicelli, S. Ferrer, and F. Comin, Phys. Rev. B 54, 8064 (1996).

${ }^{25}$ Y. Mizokawa, T. Miyasato, S. Nakamura, K. M. Geib, and C. W. Wilmsen, J. Vac. Sci. Technol. A 5, 2809 (1987).

${ }^{26}$ T. Tatsumi, M. Matsui, M. Okigawa, and M. Sekine, J. Vac. Sci. Technol. B 18, 1897 (2000).

${ }^{27}$ G. J. Coyle and G. S. Oehrlein, Appl. Phys. Lett. 47, 604 (1985).

${ }^{28}$ R. Blanc, F. Leverd, T. David, and O. Joubert, J. Vac. Sci. Technol. B 31, 051801 (2013).

${ }^{29}$ R. Blanc, C. Jenny, S. Lagrasta, F. Leverd, and O. Joubert, J. Vac. Sci. Technol. B 32, 021806 (2014).

${ }^{30}$ T. Tsutsumi, H. Kondo, M. Hori, M. Zaitsu, A. Kobayashi, T. Nozawa, and N. Kobayashi, J. Vac. Sci. Technol. A 35, $01 \mathrm{~A} 103$ (2017).

${ }^{31}$ K. Nakamura, K. Kumagai, T. Tatsumi, and K. Oshima, in Proceedings of the International Symposium on Dry Process, Jeju, Korea, 28 November 2005 (DPS, Korea, 2005), p. 99. 